Title: Variation in personality states as predicted by interpersonal context

(Accepted by the Journal of Individual Differences)

Authors: Jamie S Churchyard ${ }^{\mathrm{a}, *}$, Karen J Pine ${ }^{\mathrm{a}, \mathrm{b}}$, Shivani Sharma ${ }^{\mathrm{a}}$, and Ben (C) Fletcher ${ }^{\mathrm{a}, \mathrm{b}}$

Word count: 4,638 (including everything except this title page).

Author note:

aDepartment of Psychology, School of Life and Medical Sciences, University of Hertfordshire, UK

${ }^{\mathrm{b}}$ Department of Fashion, School of Applied Sciences, Istanbul Bilgi University, Turkey *Correspondence regarding this manuscript should be sent to Jamie Churchyard, Department of Psychology, School of Human and Social Sciences, University of West London, Brentford, London, TW8 9GA, UK. Email: Jamie.Churchyard@uwl.ac.uk

This manuscript has not been published elsewhere, and it has not been submitted simultaneously for publication elsewhere. 
Variation in personality states as predicted by interpersonal context

\begin{abstract}
Diary studies of personality have shown that personality is variable, and can help the person deal appropriately with the different interpersonal demands they encounter. This study aims to demonstrate how interpersonal context predicts personality states. Thirty six participants $(9$ male, 27 female, age $M=24.72, S D=7.11$ ) kept an online diary for one month. The diary recorded measurements of HEXACO personality states, momentary interpersonal factors including current interpersonal role (with friend, family member, partner, as employee/student, alone) and social goal orientation (socialising with others, avoidance of others, asserting yourself, personal/work achievement), and dispositional anxiety and depression. Individuals' personality states were found to vary considerably across measurements in a normal distribution. Multi-level modelling analyses showed that interpersonal factors did predict within subject personality variation. Social goal orientations had a greater relative impact than interpersonal roles. Depression had a significant effect on between subject variance in state emotionality. These findings highlight the importance of interpersonal context in predicting stable personality variation.
\end{abstract}

Keywords: Intra-individual variation, HEXACO model, personality state, interpersonal context, diary study. 


\section{Variation in personality states as predicted by interpersonal context}

This study examines variations in personality trait measures that occur in people in moment-by- moment, and examines some of the interpersonal factors that affect this variation. The prominent perspectives in personality research are trait (e.g. Ashton, Lee \& Son, 2000; McCrae \& Costa, 1996) and social-cognitive processing theories (Fletcher \& Stead, 2000; Mischel \& Shoda, 1995). Research shows that personality states measured using trait dimensions are not fixed and can vary moment-by-moment as states (Baird, Le \& Lucas, 2006; Beckmann, Wood \& Minabashian, 2010; Fleeson, 2007; Fleeson \& Gallagher, 2009). McCrae \& Costa (1996), in their five factor personality system, acknowledge that characteristic adaptations do occur. These are responses triggered by expressions of a trait that are appropriate for the current context. There is reason to believe that interpersonal factors can influence this stable variation in personality (Bleidorn, 2009; Churchyard, Pine, Sharma, \& Fletcher, 2013; Heller, Komar, \& Lee, 2007; Robinson, 2009).

How sensitive is personality expression to the specific context? The Cognitive and Affective Personality System (CAPS) theory (Mischel \& Shoda, 1995), suggests individuals' responses to particular contexts are influenced by various cognitive-affective units (CAUs) including goals and values, affects, self-regulatory plans and competencies, expectancies of outcomes, encodings of the self, others and situation, and feedback received from previously applying the behavior in similar contexts. This creates if situation - then behaviour relationships. Specific situational context learning will result in apparently different expressions of a higher order behavioral trait (a state that differs from the standard trait disposition). CAPS theory has been discussed in the interpersonal context in terms of relational selves by Andersen \& Chen, (2002), who proposed the idea that we have different selves which elicit behaviour for different relationships. 


\section{The current study}

We used a diary study method to examine which interpersonal contextual factors have a greater impact on individual variation in personality, and to consider how this variation relates to dispositional affective factors. Interpersonal contextual predictors included a range of interpersonal roles and social goal orientations. Bleidorn (2009), and Heller, Komar \& Lee (2007) have examined interpersonal roles and social goal orientations previously, although they have not yet been examined in the same study, a recommendation that Heller, Perunovic \& Reichman (2009) make. To take account of affective factors we measured dispositional anxiety and depression. Heller, Komar \& Lee, (2007) findings suggest that dispositional anxiety and depression will be positively related to emotional (neurotic) personality states but negatively related to more positive personality states such as honesty, extraversion, agreeableness, conscientiousness and openness to experience, as they previously found current mood measures of positive affect to be positively predicted by state extraversion, and negative affect to be positively predicted by state neuroticism.

We took multiple diary recording measurements of individuals' HEXACO personality states. The HEXACO personality model consists of the big-five traits and an additional honesty component (Ashton, Lee \& Son, 2000). This addition is valuable because it might be expected to show lower within-subject variation than the other states reflecting stability in levels of honesty across relational context. Honesty levels may differ between people, but might be more invariant to context within a person because of the nature of the construct being measured. This study, therefore, examines the degree of personality state variation that occurs and examines some of the important interpersonal and affective reasons for it. 


\section{Method}

\section{Participants and procedure}

Thirty-six participants took part (9 male, 27 female, age $M=24.72, S D=7.11$ ) after responding to online research recruitment sites and the University participant pool. The participants accessed the diary via a UK Bristol online survey hyperlink and were asked to fill out diary recordings at least once a day for up to one month until 30 recordings were completed. Participants were asked to leave at least five hours between entries, to avoid overlap in entries. Response rates varied between completing at least 20 of 30 possible days. Overall, 1062 repeated measurements were collected for all the participants.

\section{Measures}

HEXACO personality state items.18 bipolar adjective items were used to measure the HEXACO states. For example, to measure diligence in the conscientiousness state, lazydiligent was used. These 18 items were each measured on a 1-7 Likert scale (where in the previous example, 1 would represent extremely lazy, while 7 would represent extremely diligent). Each of the six personality states measured consisted of three items, based on three of the facet categories out of the four that form each trait in the HEXACO model (Ashton, Lee \& Son, 2000). As an example, we decided to use the following three items of insinceresincere, unfair-fair and arrogant-modest, based on the honesty facet categories of sincerity, fairness and modesty from the honesty trait of the HEXACO model. In terms of reliability, the honesty $(\alpha=.77)$, emotionality $(\alpha=.73)$ and agreeableness $(\alpha=.80)$ state measures were found to be reliable, while extraversion $(\alpha=.64)$, conscientiousness $(\alpha=.63)$, and openness to experience state measures were found to be moderately reliable $(\alpha=.67)$ across every repeated measurement for every participant. These reliability values were decent considering each state measure only consisted of three items for ease of repeated completion. 
Interpersonal role and social goal orientation markers. To measure interpersonal roles, five options were included (with friend, with family member, with partner, as an employee/student and alone). To measure social goal orientations, four options were included (socialising with others, avoidance of others, asserting yourself and personal or work achievement). These options were each rated using a Yes/No tick response option, when the participant was asked to tick which categories their activities came under within the past few hours. The interpersonal roles were drawn from those listed by Bleidorn (2009), while the social goal orientation categories were based on the outcome of a factor analysis of four social motives (affiliation, avoidance, power and achievement) onto the big-five personality traits conducted by Engeser \& Langens (2010). Affiliation was relabelled as socialising, and power relabelled as asserting yourself to make them easier to understand and applicable for the contextual measurements of this study (these labels were considered appropriate based on the factor structure and correlations Engeser \& Langens reported).

Thoughts and feelings scale. The Thoughts and Feelings scale from the FIT profiler (Fletcher \& Stead, 2000) was administered at the beginning of the study to measure dispositional anxiety and depression. This measures frequency of feeling anxious (4 items), and depressed (4 items) over the last month. Each item uses a 4 point response scale: 1 ) Never, 2) Very rarely, 3) Now and again, 4) Frequently/often. This gives total anxiety and depression scores between 0 and 12 . Both scales have been shown to display high reliability (anxiety $\alpha=0.80$, depression $\alpha=0.78$ ) and have been validated against other measures (Sharma, 2010). 


\section{Results}

To provide a descriptive measure of how personality states varied within the subject; repeated measurement standard deviations were calculated for each participant on each state. Considering these states were measured on a 7 point scale, an average state standard deviation of 0.81 (honesty), 1.03 (emotionality), 1.05 (extraversion), 0.99 (agreeableness), 0.86 (conscientiousness), or 0.82 (openness to experience) in both directions reflects a good degree of variation in personality states over repeated measures in the sample. The state scores for most individuals displayed a normal distribution around their mean score. Figure 1 provides an example of this for a participant's variation in state conscientiousness.

Figure 1 about here.

Figure 1: An example density distribution from a participant who varied in state conscientiousness (the state conscientiousness score being the mean of its three facet items).

We determined multi-models using the MLWin software (Rasbash, Charlton, Browne, Healy \& Cameron, 2009), using maximum likelihood estimation, to examine which interpersonal and affective variables predict particular personality states in multivariate multilevel regression models.

\section{Multivariate multi-level regression modelling analyses.}

Three-level multivariate regression modelling analyses with interpersonal role and social goal orientation as repeated measure predictors, and anxiety and depression as between subject predictors of personality states were conducted. The analysis procedure followed was 
based on Bleidorn (2009) analysis procedure, except with six rather than five factors, as the HEXACO model includes the additional honesty component as well as the big five. The first level is a measurement model, while levels 2 and 3 are within subject and between subject levels respectively. The main benefits of this multivariate procedure in comparison to separate univariate procedures are that it does not require balanced data or equidistant time measurement occasions, and it provides more powerful and accurate tests of the fixed effects and standard errors (Snijders \& Bosker, 1999). Multivariate analysis was also conducted as the deviations were all found to be correlated (between $r=.39$ and $r=.74$, all at least $p<.05$ ).

Variance partition coefficients were calculated at baseline to determine the ratio of variance at the within subject (level 2) and between subjects (level 3). Variance partition coefficients closer to 1 , indicate more variance at the between subject level than the within subject level. The analyses suggested that there is more within subject variance present in the honesty $(\mathrm{VPC}=0.41)$, emotionality $(0.32)$, extraversion $(0.11)$, agreeableness $(0.22)$, conscientiousness (0.35) and openness to experience states (0.39). The honesty state displayed the greatest degree of between subject variation.

These multi-level modelling analyses are performed under the assumption that the level 2 and level 3 residuals are normally distributed. Residual analyses were conducted which indicated the level 2 residuals were normally distributed for all six states, and the level 3 residuals were normally distributed for every state except honesty which displayed mild skew to the left of the distribution. As this skew was only mild, it was deemed appropriate to continue the analyses.

The interpersonal role, social goal orientation, anxiety and depression explanatory variables were applied to give fixed effects that predict variance in personality states at levels 2 and 3. In every instance of adding the repeated measures contextual predictors the $-2 \log$ 
likelihood statistic significantly decreased compared to the baseline model (at $p<.05$ at least, based on the chi square distribution). When depression was then added to the multivariate model it did not lead to a significant decrease in the -2Log likelihood statistic when compared to the baseline statistic, or in addition after adding any repeated measures predictor. However, there were several consistent patterns of significant fixed effects for depression in the multivariate model, that were worth mentioning and so these have been reported. The change in -2log likelihood statistic was most likely nonsignificant, with some fixed effects being significant due to depression only having a considerable impact on the between subject variance, of which there was little in comparison to within subject variation. When anxiety was added to the multivariate model as a single predictor or in addition after a repeated measures predictor had been added to the baseline, there was not a significant change in the 2log likelihood statistic (anxiety displayed a very similar pattern of -2LL statistics to depression). However, with anxiety no significant fixed effects were present in the full multivariate model, so the findings for anxiety have not been reported.

Table 1 reports the impact of the fixed effect of a contextual predictor $\beta_{c}$ and fixed effect of dispositional depression $\beta_{d}$ on the personality state when added to the baseline equations (for each state); and how the unexplained within subject $\sigma_{u}^{2}$ and between subject $\sigma_{v}^{2}$ variance changes after the addition of the fixed effects. To determine whether the significance of specific fixed effects was $p<.05$, the fixed effect was compared against the value of the standard error of that fixed effect multiplied by 1.96 (the $t$ statistic value that reflects $95 \%$ coverage of the normal distribution). If the effect value was greater than its standard error multiplied by 1.96 , then $p<.05$. The friend role and the personal or work achievement orientation predictors were also found to have an impact when the effect of the predictor was allowed to vary according to the participant in random slopes models. Of the models that converged when depression was added as well (some did not converge, most 
likely due to the complex structure of the data), only these two were found to be significant, and have been reported. The altered fixed effect of these two predictors and their impact on the unexplained variances has been reported separately to the results for the standard form of these two predictors in table 1.

The extraverted state was significantly predicted by every role or orientation. Extraverted states were positively predicted by the with friend role, with partner role, with family member role, as an employee/student role, socialising with others orientation, asserting yourself orientation and personal/work achievement orientation. Extraverted states were negatively predicted by the alone role and avoiding others orientation. State openness to experience was predicted by every role or orientation, except the with partner role. The effects were all in the same direction as those for the extraverted state. State agreeableness was positively predicted by the with friend role, the socialising with others and personal/work achievement orientations. Agreeableness states were negatively predicted by the alone role and avoiding others orientation. The emotionality state was negatively predicted by the socialising with others and asserting yourself orientations, but positively predicted by the avoiding others orientation. State honesty was also positively predicted by socialising with others, asserting yourself and personal/work achievement orientations, as well as being negatively predicted by the avoiding others orientation. State conscientiousness was positively predicted by the as an employee/student role, and the socialising with others, asserting yourself and personal/work achievement orientations. The unexplained within subject variance in personality state for the predictor always showed a significant decrease. When the significant random slope effects for the friend role and achievement orientation were added to the baseline model, the within subject variance decreased, but the unexplained between subject variance also increased. This means part of the within subject variance in 
personality state is sensitive to each participant's expression of the particular predictor considered.

When depression was entered with all but one of the repeated measure predictors (the exception being the with friend predictor when random slope effects were applied), it showed a significant positive fixed effect on state emotionality, with the unexplained between subject variance decreasing considerably. The unexplained within subject variance also showed a small decrease. Depression was found to negatively predict state extraversion, agreeableness, conscientiousness and openness to experience, and positively predict state emotionality, when entered with the achievement predictor (when random slope effects were applied). In the state extraversion, agreeableness and conscientiousness models the unexplained between subject variance increased, but decreased in the state emotionality and openness to experience models.

Table 1 about here. 


\section{Discussion}

Previous diary studies have shown that behavior within five factor personality states varies (Fleeson \& Gallagher, 2009), and that it can be predicted by context (Bleidorn, 2009; Fleeson, 2007; Heller, Komar \& Lee, 2007). The aim of this study was to further identify and compare the role of moment-by-moment interpersonal factors in the variability of personality. We found good evidence to support personality varying moment-by-moment, as measured by the HEXACO model, and that the variation is predicted by who the individual is with and what their goals are.

The attributes in the traditional five factor model followed the variance partition pattern displayed in previous research (Bleidorn, 2009; Fleeson, 2007; Fleeson \& Gallagher, 2009; Heller, Komar \& Lee, 2007). The additional honesty state was found to display a greater degree of between subject variation in the variance than the other states (although again there was still considerable within subject variation). Honesty might be expected to be more stable than the other states- as honesty is required across all interpersonal contexts. If an individual's honesty varied to the same degree as the other states this would likely indicate poor interpersonal functioning. There was mild skew of the level 3 honesty residuals towards the left of the distribution, indicating between subject honesty was high on average, supporting this.

The results of the multi-level modelling strongly support interpersonal roles or social goal orientations predicting personality states. Relative to specific interpersonal roles, the social goal orientations generally had a greater impact on personality states. Personality states with more positive connotations (higher honesty, extraversion, conscientiousness and openness to experience) were positively predicted by roles and orientations focused on engaging with other people and achieving, while the opposing alone role and avoiding others 
orientation negatively predicted these states (honesty, extraversion, agreeableness, openness to experience). The alone role and avoiding others orientation were found to positively predict state emotionality. The finding that particular personality states are predicted by specific roles and goals provides support for the view that situational dispositions are a result of the individual's experiences and feedback from the social environment (as proposed within CAPS theory, Mischel \& Shoda, 1995). Although the interpersonal roles and social goal orientations displayed different relative effect strengths across states, the effects displayed similar directions in terms of positive and negative behaviour states, suggesting they are associated and important to consider together as suggested by Heller, Perunovic \& Reichman (2009). The difference in strength of the predictors across the different states suggests there is differentiation in degree of state behaviour by interpersonal context. For example, the with friend role had a much stronger impact on extraversion, in comparison to agreeableness and openness to experience, whereas the personal or work achievement orientation had a much stronger impact on state conscientiousness, when compared to honesty, extraversion, agreeableness and openness to experience. This suggests some states were particularly facilitated by certain interpersonal factors. As these are fixed effects, relevant across participants, this indicates that they are appropriate ways to act in particular contexts.

The FIT Science framework would suggest that variability or flexibility in behavioral states has a beneficial effect on the individual's engagement with their differing environments (Fletcher \& Stead, 2000). This is supported by the lack of any predictive effects for anxiety on personality states and the finding here that depression only consistently predicted state emotionality. These findings have interesting implications for behavior change approaches and therapies because behavioral flexibility - or greater variation in personality states - is required to adapt to different circumstances (Fletcher, Hanson, Pine \& Page, 2011). 


\section{Limitations and future directions.}

We only examined a limited range of predictors, and there may have been benefits of splitting the as employee/student and personal/work achievement markers into separate marker categories, or adding others. However, every addition would have expanded the demands on the participants and this would itself introduce other difficulties. Although we examined both interpersonal roles and social goal orientations together, we did not report interaction analyses, due to the excessive amount of analysis entailed for all the potential combinations of predictors. To explore the potential interactions, future studies could examine specific interpersonal roles and social goal orientations that are likely to interact, based on these findings. For example, the with friend role and socialising with others orientation are likely to interact based on their contextual compatibility. Also those roles and orientations sharing a similar directionality in findings in these analyses could be considered.

\section{Conclusion.}

Overall, this study provides support for people displaying meaningful intra-individual variation across all HEXACO personality states, which were predicted by both interpersonal role and social goal orientation contextual variables. Anxiety levels did not predict the expression of personality state, although dispositional depression did so to a limited degree. Taken together, the results provide support for considering the implications of moment-bymoment fluctuations in personality state due to interpersonal contextual factors. 


\section{References}

Andersen, S. M., \& Chen, S. (2002). The Relational Self: An Interpersonal Social-Cognitive Theory. Psychological Review, 109, (4), 619-645.

Ashton, M. C., Lee, K., \& Son, C. (2000). Honesty as the Sixth Factor of Personality: Correlations with Machiavellianism, Primary Psychopathy, and Social Adroitness. European Journal of Personality, 14, (4), 359-368.

Baird, B. M., Le, K., \& Lucas, R. E. (2006). On the Nature of Intra-individual Personality Variability: Reliability, Validity, and Associations With Well-Being. Journal of Personality and Social Psychology, 90, (3), 512-527.

Beckmann, N., Wood, R. E., \& Minbashian, A. (2010). It depends how you look at it; On the relationship between neuroticism and conscientiousness at the within- and betweenperson levels of analysis. Journal of Research in Personality, 44, 593-601.

Bleidorn, W. (2009). Linking Personality States, Current Social Roles and Major Life Goals. European Journal of Personality, 23, (6), 509-530.

Churchyard, J. S., Pine, K. J., Sharma, S., \& Fletcher, B. (C). (2013). Construction by interpersonal context, and relationship to psychological outcomes. Journal of Constructivist Psychology, 26, (4), 306-315.

Engeser, S., \& Langens, T. (2010). Mapping explicit social motives of achievement, power and affiliation onto the five-factor model of personality. Scandinavian Journal of Psychology, 51, 309-318.

Fleeson, W. (2007). Situation-based contingencies underlying trait-content manifestation in behavior. Journal of Personality, 75, (4), 825-861. 
Fleeson, W., \& Gallagher, P. (2009). The Implications of Big Five Standing for the Distribution of Trait Manifestation in Behavior: Fifteen Experience-Sampling Studies and a Meta-Analysis. Journal of Personality and Social Psychology, 97, (6), 10971114

Fletcher, B (C), Hanson, J., Pine, K. J., \& Page, N. (2011). FIT- Do Something Different: A new psychological intervention tool for facilitating weight loss. Swiss Journal of Psychology, 70, (1), 25-34.

Fletcher, B. (C)., \& Stead, B. (2000). (Inner) FITness \& The FIT Corporation. International Thomson Press: London.

Heller, D., Komar, J., \& Lee, W. B. (2007). The Dynamics of Personality States, Goals, and Well-being. Personality and Social Psychology Bulletin, 33, (6), 898-910.

Heller, D., Perunovic, W. Q. E., \& Reichman, D. (2009). The future of person-situation integration in the interface between traits and goals: A bottom-up framework. Journal of Research in Personality, 43, 171-178.

McCrae, R. R., \& Costa, P. T. Jr. (1996). Toward a new generation of personality theories: Theoretical contexts for the five-factor model. In J. S. Wiggins (Ed.), The five-factor model of personality: Theoretical perspectives (pp. 51-87). New York: Guilford Press.

Mischel, W., \& Shoda, Y. (1995). A Cognitive-Affective System Theory of Personality: Reconceptualizing Situations, Dispositions, Dynamics, and Invariance in Personality Structure. Psychological Review, 102, (2), 246-268.

Rasbash, J., Charlton, C., Browne, W.J., Healy, M. \& Cameron, B. (2009). MLwiN Version 2.1. Centre for Multilevel Modelling, University of Bristol. 
Robinson, O. C. (2009). On the Social Malleability of Traits Variability and Consistency in Big 5 Trait Expression Across Three Interpersonal Contexts. Journal of Individual Differences, 30, (4), 201-208.

Sharma, S. (2010). FIT Science for Improving Family Functioning and Parenting Stress. Unpublished doctoral dissertation. University of Hertfordshire, Hatfield, UK.

Snijders, T. A. B., \& Bosker, R. J. (1999). Multi-level analysis: An introduction to basic and advanced multi-level modelling. London: Sage. 


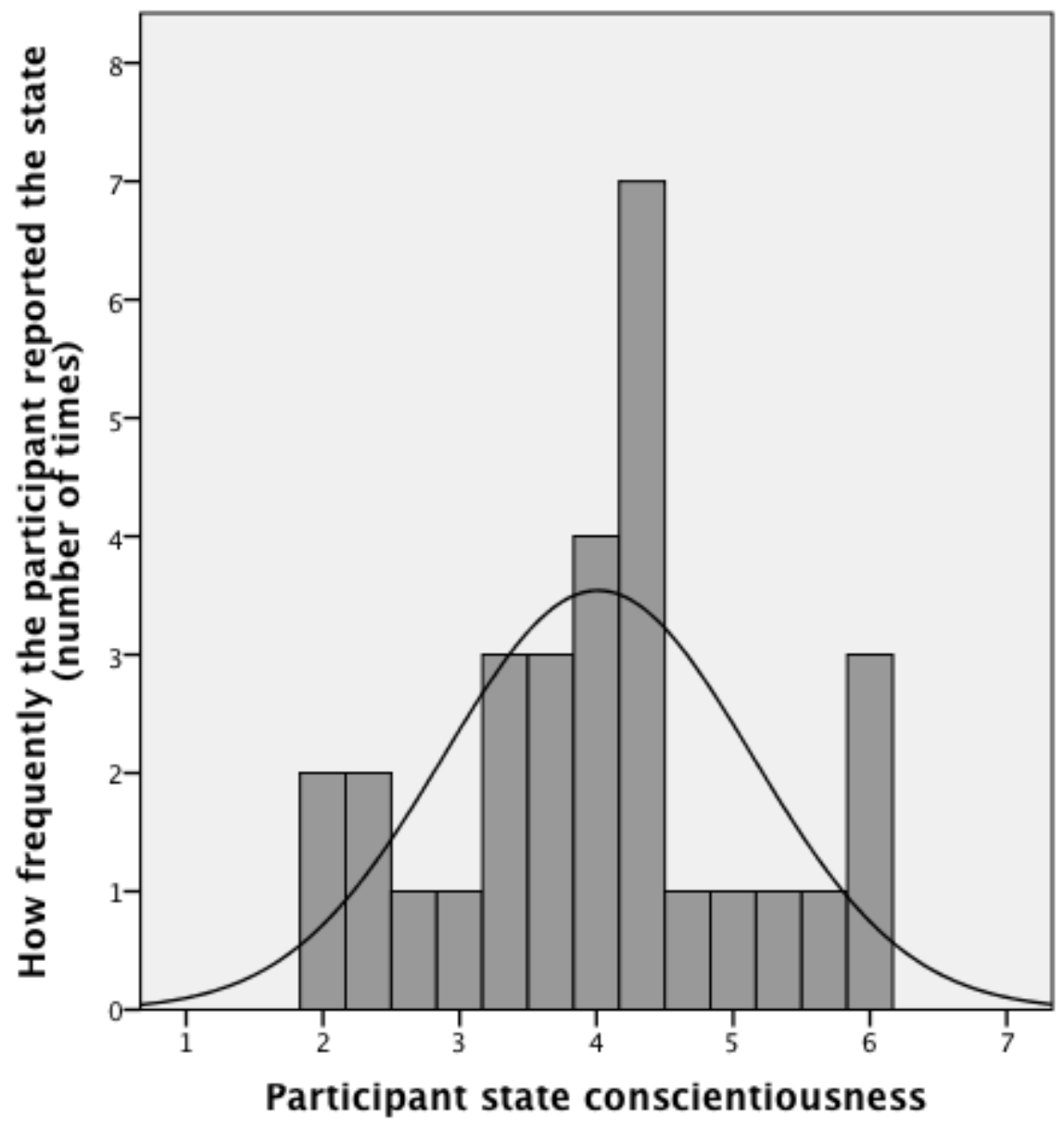

Figure 1. 
Table 1: The fixed effects of each contextual predictor and depression on the HEXACO states.

\begin{tabular}{|c|c|c|c|c|c|c|c|c|c|c|c|c|c|c|}
\hline \multicolumn{2}{|c|}{ State } & \multirow[t]{2}{*}{ Baseline } & \multirow{2}{*}{$\begin{array}{c}\text { Depression } \\
\text { (DP) }\end{array}$} & \multirow{2}{*}{$\begin{array}{l}\text { Friend } \\
\text { and DP }\end{array}$} & \multirow{2}{*}{$\begin{array}{c}\text { Friend (k) } \\
\text { and DP }\end{array}$} & \multirow{2}{*}{$\begin{array}{l}\text { Partner } \\
\text { and DP }\end{array}$} & \multirow{2}{*}{$\begin{array}{c}\text { FM and } \\
\text { DP }\end{array}$} & \multirow{2}{*}{$\begin{array}{c}\text { ES and } \\
\text { DP }\end{array}$} & \multirow{2}{*}{$\begin{array}{c}\text { Alone and } \\
\text { DP }\end{array}$} & \multirow[t]{2}{*}{ SWO and DP } & \multirow[t]{2}{*}{$\mathrm{AO}$ and $\mathrm{DP}$} & \multirow[t]{2}{*}{ AY and DP } & \multirow{2}{*}{$\begin{array}{c}\text { Achieving } \\
\text { and DP }\end{array}$} & \multirow{2}{*}{$\begin{array}{l}\text { Achieving } \\
\text { (k) and DP }\end{array}$} \\
\hline & & & & & & & & & & & & & & \\
\hline \multirow[t]{6}{*}{$\mathrm{H}$} & $\beta_{\mathrm{c}}$ & N/A & N/A & 0.114 & 0.093 & 0.147 & -0.006 & 0.097 & -0.099 & 0.214 & -0.283 & 0.208 & 0.166 & 0.166 \\
\hline & & N/A & N/A & $(0.061)$ & $(0.066)$ & $(0.080)$ & $(0.064)$ & $(0.064)$ & $(0.061)$ & $(0.059)$ & $(0.072)$ & $(0.060)$ & $(\mathbf{0 . 0 5 8})$ & $(0.072)$ \\
\hline & $\beta_{\mathrm{d}}$ & N/A & -0.044 & -0.042 & -0.002 & -0.039 & -0.044 & -0.043 & -0.044 & -0.038 & -0.040 & -0.041 & -0.042 & -0.040 \\
\hline & & N/A & $(0.053)$ & $(0.053)$ & $(0.048)$ & $(0.053)$ & $(0.053)$ & $(0.053)$ & $(0.053)$ & $(0.053)$ & $(0.053)$ & $(0.053)$ & $(0.053)$ & $(0.051)$ \\
\hline & $\sigma_{u p p}^{z}$ & 0.774 & 0.774 & 0.771 & 0.767 & 0.772 & 0.774 & 0.773 & 0.773 & 0.765 & 0.763 & 0.765 & 0.769 & 0.754 \\
\hline & $\sigma_{v p}^{z}$ & 0.533 & 0.522 & 0.529 & 0.551 & 0.518 & 0.523 & 0.523 & 0.517 & 0.517 & 0.521 & 0.529 & 0.515 & 0.565 \\
\hline \multirow[t]{6}{*}{$\mathrm{E}$} & $\beta_{\mathrm{c}}$ & N/A & N/A & -0.062 & -0.075 & -0.180 & -0.087 & 0.109 & -0.002 & -0.248 & 0.315 & -0.151 & -0.037 & -0.014 \\
\hline & & N/A & N/A & $(0.075)$ & $(0.075)$ & $(0.097)$ & $(0.078)$ & $(0.078)$ & $(0.075)$ & $(\mathbf{0 . 0 7 3 )}$ & $(\mathbf{0 . 0 8 8})$ & $(0.074)$ & $(0.072)$ & $(0.102)$ \\
\hline & $\beta_{\mathrm{d}}$ & N/A & 0.116 & 0.114 & 0.092 & 0.110 & 0.118 & 0.118 & 0.116 & 0.109 & 0.111 & 0.113 & 0.115 & 0.129 \\
\hline & & N/A & $(0.052)$ & $(\mathbf{0 . 0 5 3})$ & $(0.050)$ & $(0.052)$ & $(0.052)$ & $(0.052)$ & $(0.052)$ & $(0.052)$ & $(0.052)$ & $(0.052)$ & $(\mathbf{0 . 0 5 3 )}$ & $(0.045)$ \\
\hline & $\sigma_{u p}^{z}$ & 1.166 & 1.166 & 1.165 & 1.165 & 1.162 & 1.165 & 1.165 & 1.166 & 1.153 & 1.152 & 1.161 & 1.166 & 1.123 \\
\hline & $\sigma_{i p p}^{z}$ & 0.570 & 0.497 & 0.503 & 0.508 & 0.486 & 0.495 & 0.479 & 0.497 & 0.495 & 0.487 & 0.495 & 0.497 & 0.528 \\
\hline \multirow[t]{6}{*}{$X$} & $\beta_{c}$ & N/A & N/A & 0.569 & 0.604 & 0.425 & 0.213 & 0.225 & -0.613 & 0.734 & -0.552 & 0.567 & 0.168 & 0.169 \\
\hline & & N/A & N/A & $(0.072)$ & (0.113) & $(0.092)$ & $(0.076)$ & $(0.076)$ & $(0.072)$ & $(0.070)$ & $(0.087)$ & $(0.072)$ & $(0.071)$ & $(0.100)$ \\
\hline & $\beta_{\mathrm{d}}$ & N/A & -0.053 & -0.040 & -0.010 & -0.038 & -0.060 & -0.050 & -0.050 & -0.033 & -0.044 & -0.044 & -0.051 & -0.072 \\
\hline & & N/A & $(0.030)$ & $(0.032)$ & $(0.028)$ & $(0.031)$ & $(0.031)$ & $(0.031)$ & $(0.029)$ & $(0.033)$ & $(0.031)$ & $(0.031)$ & $(0.030)$ & $(0.026)$ \\
\hline & $\sigma_{u p}^{z}$ & 1.200 & 1.200 & 1.130 & 1.072 & 1.169 & 1.190 & 1.189 & 1.123 & 1.080 & 1.153 & 1.127 & 1.194 & 1.146 \\
\hline & $\sigma_{i p}^{z}$ & 0.155 & 0.140 & 0.156 & 0.165 & 0.150 & 0.146 & 0.145 & 0.128 & 0.169 & 0.142 & 0.146 & 0.136 & 0.228 \\
\hline
\end{tabular}


Table 1 continued: The fixed effects of each contextual predictor and depression on the HEXACO states.

\begin{tabular}{|c|c|c|c|c|c|c|c|c|c|c|c|c|c|c|}
\hline \multicolumn{2}{|c|}{ State } & \multirow[t]{2}{*}{ Baseline } & \multirow{2}{*}{$\begin{array}{c}\text { Depression } \\
\text { (DP) }\end{array}$} & \multirow{2}{*}{$\begin{array}{l}\text { Friend } \\
\text { and DP }\end{array}$} & \multirow{2}{*}{$\begin{array}{l}\text { Friend (k) } \\
\text { and DP }\end{array}$} & \multirow{2}{*}{$\begin{array}{l}\text { Partner } \\
\text { and DP }\end{array}$} & \multirow{2}{*}{$\begin{array}{c}\text { FM and } \\
\text { DP }\end{array}$} & \multirow{2}{*}{$\begin{array}{c}\text { ES and } \\
\text { DP }\end{array}$} & \multirow{2}{*}{$\begin{array}{c}\text { Alone and } \\
\text { DP }\end{array}$} & \multirow[t]{2}{*}{ SWO and DP } & \multirow[t]{2}{*}{$\mathrm{AO}$ and $\mathrm{DP}$} & \multirow[t]{2}{*}{$\mathrm{AY}$ and DP } & \multirow{2}{*}{$\begin{array}{l}\text { Achieving } \\
\text { and DP }\end{array}$} & \multirow{2}{*}{$\begin{array}{l}\text { Achieving } \\
\text { (k) and DP }\end{array}$} \\
\hline & & & & & & & & & & & & & & \\
\hline \multirow[t]{6}{*}{$\mathrm{A}$} & $\beta_{\mathrm{c}}$ & N/A & N/A & 0.282 & 0.280 & 0.153 & -0.033 & 0.047 & -0.196 & 0.455 & -0.453 & 0.074 & 0.175 & 0.166 \\
\hline & & N/A & N/A & $(0.070)$ & $(0.083)$ & $(0.090)$ & $(0.073)$ & $(0.074)$ & $(0.071)$ & $(0.068)$ & $(0.083)$ & $(0.070)$ & $(0.068)$ & $(0.073)$ \\
\hline & $\beta_{\mathrm{d}}$ & N/A & -0.063 & -0.056 & -0.025 & -0.058 & -0.062 & -0.062 & -0.062 & -0.050 & -0.056 & -0.062 & -0.061 & -0.082 \\
\hline & & N/A & $(0.040)$ & $(0.041)$ & $(0.034)$ & $(0.040)$ & $(0.040)$ & $(0.040)$ & $(0.039)$ & $(0.040)$ & $(0.040)$ & $(0.040)$ & $(0.040)$ & $(\mathbf{0 . 0 3 4 )}$ \\
\hline & $\sigma_{u p}^{z}$ & 1.067 & 1.067 & 1.048 & 1.037 & 1.063 & 1.066 & 1.066 & 1.060 & 1.020 & 1.036 & 1.065 & 1.059 & 1.055 \\
\hline & $\sigma_{\mathrm{vp}}^{2}$ & 0.297 & 0.275 & 0.293 & 0.352 & 0.272 & 0.275 & 0.276 & 0.257 & 0.282 & 0.271 & 0.278 & 0.274 & 0.345 \\
\hline \multirow[t]{6}{*}{$\mathrm{C}$} & $\beta_{\mathrm{c}}$ & N/A & N/A & 0.112 & 0.091 & -0.062 & -0.034 & 0.300 & -0.119 & 0.177 & -0.106 & 0.358 & 0.519 & 0.525 \\
\hline & & N/A & N/A & $(0.062)$ & $(0.073)$ & $(0.081)$ & $(0.065)$ & $(0.065)$ & $(0.062)$ & $(0.061)$ & $(0.074)$ & $(0.061)$ & $(0.057)$ & $(0.074)$ \\
\hline & $\beta_{\mathrm{d}}$ & N/A & -0.075 & -0.072 & -0.033 & -0.077 & -0.074 & -0.070 & -0.074 & -0.070 & -0.073 & -0.069 & -0.068 & $-\mathbf{- 0 . 0 8 9}$ \\
\hline & & N/A & $(0.047)$ & $(0.047)$ & $(0.044)$ & $(0.047)$ & $(0.047)$ & $(0.048)$ & $(0.046)$ & $(0.047)$ & $(0.047)$ & $(0.047)$ & $(0.045)$ & $(\mathbf{0 . 0 3 9 )}$ \\
\hline & $\sigma_{\text {up }}^{z}$ & 0.801 & 0.801 & 0.798 & 0.787 & 0.800 & 0.800 & 0.783 & 0.799 & 0.794 & 0.799 & 0.776 & 0.744 & 0.726 \\
\hline & $\sigma_{i p}^{2}$ & 0.434 & 0.404 & 0.407 & 0.408 & 0.408 & 0.403 & 0.425 & 0.389 & 0.404 & 0.398 & 0.396 & 0.375 & 0.438 \\
\hline \multirow[t]{6}{*}{$\mathrm{O}$} & $\beta_{\mathrm{c}}$ & N/A & N/A & 0.148 & 0.150 & 0.125 & 0.153 & 0.169 & -0.121 & 0.185 & -0.267 & 0.280 & 0.223 & 0.215 \\
\hline & & N/A & N/A & $(\mathbf{0 . 0 6 0})$ & $(0.062)$ & $(0.078)$ & $(\mathbf{0 . 0 6 3 )}$ & $(\mathbf{0 . 0 6 3 )}$ & $(0.060)$ & $(0.059)$ & $(0.071)$ & $(0.059)$ & $(0.057)$ & $(0.068)$ \\
\hline & $\beta_{d}$ & N/A & -0.089 & -0.085 & -0.090 & -0.085 & -0.093 & -0.086 & -0.088 & -0.084 & -0.085 & -0.084 & -0.086 & -0.095 \\
\hline & & N/A & $(0.049)$ & $(0.049)$ & 0.046 & $(0.048)$ & $(0.049)$ & $(0.049)$ & $(0.049)$ & $(0.050)$ & $(0.049)$ & $(0.048)$ & $(0.048)$ & $(0.046)$ \\
\hline & $\sigma_{u p}^{z}$ & 0.750 & 0.750 & 0.745 & 0.746 & 0.748 & 0.745 & 0.745 & 0.747 & 0.742 & 0.739 & 0.734 & 0.740 & 0.728 \\
\hline & $\sigma_{v p}^{Z}$ & 0.486 & 0.443 & 0.449 & 0.499 & 0.430 & 0.444 & 0.441 & 0.442 & 0.454 & 0.444 & 0.420 & 0.430 & 0.418 \\
\hline
\end{tabular}


Note: Each column represents a single multivariate model. Each cell contains in descending order the contextual fixed effect $\beta_{c}$, SE of contextual fixed effect (in brackets), depression fixed effect $\beta_{\mathrm{d}}, \mathrm{SE}$ of depression fixed effect (in brackets), unexplained within subject variance $\left(\sigma_{\mathrm{up}}^{\mathrm{z}}\right)$, in italics, and unexplained between subject variance $\sigma_{\mathrm{vp} p}^{\mathrm{E}}$ in that order. $\mathrm{H}=\mathrm{Honesty}, \mathrm{E}=$ Emotionality, $\mathrm{X}=$ Extraversion, $\mathrm{A}=$ Agreeableness, $\mathrm{C}=$ Conscientiousness, $\mathrm{O}=$ Openness to experience. $\mathrm{FM}=$ Family member, $\mathrm{ES}=$ Employee/student, $\mathrm{SWO}=$ Socialising with others, AO = Avoiding others, AY = Asserting yourself. Friend $(\mathrm{k})$ and Achieving $(\mathrm{k})$ are the contextual effects allowed to vary by participant. Fixed effect and SE values in bold are significant at the 0.05 level at least. The intercepts were similar across models, considerable change to the intercept only occurred for very strong effects on particular states (extraversion mainly). 